\title{
Politique
}

Politique

\section{Michel LeNet, L'État annonceur : techniques, doctrine et morale de la communication sociale, Paris : les éditions d'organisation, 1981, 284 p.}

\section{Michèle Massie}

Volume 1, numéro 2, automne 1982

Les médias et les pouvoirs

URI : https://id.erudit.org/iderudit/040414ar

DOI : https://doi.org/10.7202/040414ar

Aller au sommaire du numéro

Éditeur(s)

Société québécoise de science politique

ISSN

0711-608X (numérique)

Découvrir la revue

Citer ce compte rendu

Massie, M. (1982). Compte rendu de [Michel LeNet, L'État annonceur :

techniques, doctrine et morale de la communication sociale, Paris : les éditions d’organisation, 1981, 284 p.] Politique, 1(2), 198-200.

https://doi.org/10.7202/040414ar d'utilisation que vous pouvez consulter en ligne.

https://apropos.erudit.org/fr/usagers/politique-dutilisation/ 
Michel LeNet, L'État annonceur: teçbniques, doctrine et morale de la communication sociale, Paris: les éditions d'organisation, 1981, $284 \mathrm{p}$.

Depuis une dizaine d'années, les nouveaux experts du marketing social et politique nous font miroiter leur «science». 
Cet ouvrage se situe à la suite d'ouvrages écrits sur le nouveau phénomène politique de la mise en marché des produits politiques, qu'il s'agisse des politicien(ne)s, des politiques ou des comportements. Comme ses prédécesseurs, l'auteur est un expert en communication sociale, nouvelle formule persuasive à la disposition des États dits avancés. La communication sociale englobe les efforts de la propagande religieuse et politique pour réaliser les attentes de gouvernements qui sont de plus en plus en quête de formules «souples" pour gouverner.

«L'État a deux pouvoirs: convaincre et contraindre. Le second représente l'échec du premier.» (p. 15)

L'auteur défend cette thèse et nous explique par des études comparées sur les diverses expériences de persuasion en Amérique, en Europe et au Japon comment les démocraties doivent résoudre le problème de communication citoyen(ne) - État dans l'élaboration des décisions politiques pour fixer les paramètres de notre vie en société.

Nouvel enjeu du pouvoir politique, la communication sociale devient ici le moyen le plus efficace et le plus rentable pour assurer la concertation de l'opinion au sein de la société et l'élimination des maux de notre humanité.

Le discours tenu en ces quelques deux cents pages rend bien la préoccupation du nouveau courant sur la rationalisation administrative du secteur public qui privilégie la rationalité, l'efficacité et la revalorisation de l'action étatique.

Dans la première partie de son ouvrage, LeNet fait état du bilan des grandes campagnes menées par divers gouvernements pour «vaincre les maux sociaux» (tabagisme, alcoolisme, accidents de la route, etc.). Il met en valeur les nouvelles méthodes et techniques aptes à perfectionner l'effort communicationnel du gouvernement ainsi qu'à réaliser la volonté politique dans l'implantation de réglementations appropriées. 
Deuxièmement, l'auteur explique l'opérationalisation des objectifs communicationnels en présentant une synthèse des travaux récents portant sur les diverses composantes de l'action de communiquer: le choix du thème, l'élaboration du message, la conception du slogan et du symbole, la fréquence et la durée de la communication, l'achat des médias les plus aptes à la véhiculer.

La lectrice demeure toutefois perplexe devant cet enthousiasme candide de l'auteur vis-à-vis la portée de cette action visant à atteindre un bien-être collectif... Malgré le fait que LeNet consacre la dernière partie de son ouvrage à philosopher sur la portée du "conseil social» et sur ses bienfaits, on ressent un certain vide. Il ne répond pas aux questions fondamentales soulevées par le phénomène qu'il décrit allègement. Comment justifier cette appropriation étatique de moyens ayant comme seul but de modifier les comportements? Par le vote, les citoyens(ne)s accordent-ils(elles) réellement au gouvernement élu ce droit de regard absolu sur la façon dont ils ou elles doivent vivre en société? Comment peut-on croire à cette image de paternalisme bienveillant lorsque la machine étatique est ellemême la proie des luttes de pouvoir entre politique et administration et de lacunes au niveau de l'information et des contrôles sur l'action gouvernementale globale? Finalement, comment le contrôle externe sur cette action communicationnelle politique va-t-il se faire? Et, par qui?

Michelle Massie 